\title{
ENERGETIC \& EXERGETIC ANALYSIS OF A PARABOLIC TROUGH: CONCENTRATED SOLAR POWER PLANT
}

\author{
Mohit Nagpal* \\ University of Petroleum \& Energy Studies, Dehradun, Uttarakhand, India \\ mnagpal@ddn.upes.ac.in \\ Rajesh Maithani \\ University of Petroleum \& Energy Studies, Dehradun, Uttarakhand, India \\ rmaithani@ddn.upes.ac.in \\ Suresh Kumar \\ Shri Vishwakarma Skill University, Haryana, India \\ Suresh.kumar@svsu.ac.in
}

Article history: Received 15 July 2021, Received in revised form 4 August 2021, Accepted 5 August 2021, Available online 6 August 2021

\begin{abstract}
Solar energy is the most affordable source of energy. Parabolic trough systems are used to concentrate and extract heat, therefore it's very significant to analyse its performance in terms of energy and exergy. Exergy based analysis of the system ensures the eradication of losses, resulting in the yield of energy of the highest quality. In this paper, an investigation has been carried out using numerical simulation with an objective of analysis of Parabolic Trough Collectors on the basis of energy and exergy. Detailed second law analysis has been performed by varying the system and operating parameters through computer simulation. Exergy output has been determined by analysing the effect of major system parameters, namely, mirror reflectivity, glass transmissivity, absorptivity, the diameter of glass envelop, and the receiver. The operating parameters considered in the investigation are insolation and temperature rise parameters. The extensive investigation of the parabolic trough of a concentrated solar power plant for various design parameters in the range of operating parameters reveals that it is beneficial to operate the system at higher temperature as opposed to the preference of the operating system at lower temperature from purely thermal considerations.
\end{abstract}

\section{Keyword}

solar energy, exergy, thermal efficiency, heat gain, heat losses, parabolic trough, collectors

\section{Introduction}

Efforts had been made by many researchers to further improve solar power generation technology. Numerical simulation is performed for a power plant of $30 \mathrm{MW}$ PT-SEGS. The analysis resulted in revealing that the variation of steam and heat transfer fluid (HTF) optimum temperature at different insolation. Solar radiation has a significant influence on the range of optimum temperature [1]. Kalogirous et al. [2] and Zarza et al. [3] investigate the PTC systems used for the generation of steam. The studies revealed that for steam generation, $48.6 \%$ of the insolation impending on the parabolic trough collector was utilized and the rest were losses, which were dissipated to the environment in various forms. The major losses were collection losses approximated to be $41 \%$, and thermal losses were near about 7\%. Prabhu [4] simulated and compared the Organic Rankine cycle parabolic trough with the steam Rankine cycle. The outcome indicated that at the average summer temperature, the steam Rankine cycle was much efficient and performed 15-25\% better than the ORC. Zhiyong Wu et al. [5] simulated the receiver temperature, which was performed with the help of MCRT (multi-core run time) and fluent software. The solar radiation absorbed, properties of HTF and optical properties of the receiver are the parameters considered. D. Canavarro et al. [6] investigate optical model of the large parabolic trough. The radius of the evacuated tube was $70 \mathrm{~mm}$, which resulted in a considerable increase in concentration, even without changing the acceptance angle of the optic. The new solutions represented a potential reduction in the field costs or even in O\&M. Siqueira et al. [7] evaluated the thermal performance of the concentrator with the help of simulation software varying the parameters of the concentrator. The simulation program proved to be a powerful design tool for determining the thermal efficiency, thermal losses, and optical loss. Guzman et al. [8] calculated the solar radiation potential of Barranquilla, Colombia by simulation with system advisor model. The direct and beam radiation data is fetched from NASA-SSE. The energy storage system is incorporated in analysis and optimum size minimization methods is followed for Levelized Cost of Energy (LCOE) sensitivity analysis. 
Messai et al. [9] studied parabolic trough solar power plants in different Algerian places for analyzing the usable electricity and an economic study and suggested a solution to minimize the Levelized cost of electricity. Pidaparthi and Prasad [10], demonstrated the development and installation of a solar thermal parabolic trough field of $3 \mathrm{MW}$ with the help of Abengoa as shown in Fig 6. The first one of its kind parabolic trough power plant in India was erected with the HTF used as Therminol VP-1 having a temperature range of 285 - 673 Kelvin. Controllers were installed in the plant to track the sun's real-time position for optimizing the energy absorption with no release of $\mathrm{CO}_{2}$ into the atmosphere. The total covered area is approx. $8000 \mathrm{~m}^{2}$ with and the total length of the collector is 1500 meters. Mustapha et.al [11] used mathematical analysis on various elements of the parabolic trough integrated on solar thermal power plant. Such a model was the theoretical transcription of the first principle of the thermodynamics applied to each part of the collector. Premjit et al. [12] numerically studied the parabolic trough receiver with an outer vacuum shell's performance, whereas Munoz et al. [13] present solar linear thermal collectors with thermal regime. Various simulation models have been developed through Engineering Equation Solvers (EES) and are validated Markus Eck, Tobias Hirsch [14], Fadar et al [15], Garcia et al. [16], Tsai and Lin [17] simulated different kinds of reflectors of a PTC collector using solid works to obtain the optimum thermal efficiency. Gupta and Kaushik [18] proposed an idea of direct steam generation solar power plant; different components of PTC were analyzed for energy and exergy performance. The maximum energy loss resulted in the condenser whereas the exergy loss was minimum in the collector. Aljundi [19] analyzed the Al-Hossien power plant in Jordan on the basis of energy and exergy factor and the outcome revealed maximum exergy destruction in the boiler (77\%), followed by turbine (13\%). Reddy et al. [20] perform energy and exergy analysis of components for different thermal power plants. Bespalko et al. [21] compared technologies for heat storage that can be utilized for unstable solar heat sources. The study reveals, sensible heat storage being the most appropriate for concentrated solar thermal power plant.

\section{Methods}

Parabolic trough model

The present study deals with the energetic optimization of parabolic trough collector. A wide range of insolation in the range of 500 to $1000 \mathrm{~W} / \mathrm{m}^{2}$ is considered depending on the location where the plant will be operated. Various studies reported the analysis of components of PTC that yielded the maximum thermal efficiency. The thermal and energetic performance of the parabolic trough depends upon several systems and operating parameters. System parameters can be categorized into the fixed and variable parameters.

Fixed parameters (Table 1) do not substantially influence the thermal and energetic performance. Variable parameters (Table 2) are proposed for investigation and the range of parameters has been selected based on the literature related to the design of the parabolic trough of CSPP. Table 3 shows the range of operating parameters.

Table 1. Fixed Parameters

\begin{tabular}{|l|l|l|l|}
\hline S. No. & Description & Parameter & Value \\
\hline 1 & Width of module $(\mathrm{m})$ & $\mathrm{W}$ & 5.76 \\
\hline 2 & Length of module $(\mathrm{m})$ & Lc & 12.27 \\
\hline 3 & Mirror Length $(\mathrm{m})$ & $\mathrm{L}$ & 11.9 \\
\hline 4 & Intercept factor & $\mathrm{IF}$ & 0.92 \\
\hline 5 & Emissivity of Glass Cover & $\epsilon_{\mathrm{c}}$ & 0.90 \\
\hline 6 & Outer glass Diameter $(\mathrm{m})$ & $\mathrm{D}_{\mathrm{co}}$ & 0.115 \\
\hline 7 & Inner Glass Diameter $(\mathrm{m})$ & $\mathrm{D}_{\mathrm{ci}}$ & 0.109 \\
\hline 8 & Outer absorber Diameter & $\mathrm{D}_{\mathrm{o}}$ & 0.070 \\
\hline
\end{tabular}

Table 2. Variable Parameters

\begin{tabular}{|l|l|l|l|}
\hline S. No. & Description & Parameter & Value \\
\hline 1 & Mirror reflectivity & $\rho$ & $0.72-0.92$ \\
\hline 2 & Transmissivity-absorptivity product & $\tau \alpha$ & $0.74-0.94$ \\
\hline 3 & Inner absorber Diameter & $\mathrm{Di}_{\mathrm{i}}$ & $0.045-0.065$ \\
\hline
\end{tabular}


Table 3. Operational Parameters

\begin{tabular}{|l|l|l|l|}
\hline S. No. & Description & Parameter & Value \\
\hline 1 & Insolation $\left(\mathrm{W} / \mathrm{m}^{2}\right)$ & $\mathrm{I}$ & $500-1000$ \\
\hline 2 & $\begin{array}{l}\text { Temperature difference between inlet \& } \\
\text { oulet.(K) }\end{array}$ & $\Delta \mathrm{T}$ & $50-200$ \\
\hline
\end{tabular}

The total solar power input to the collector system of the parabolic trough is $Q_{1}$, which is calculated as

$$
Q_{I}=I \times A_{a} \times N_{c} \times N_{r} \times N_{m}
$$

$$
A_{a}=\left(W-D_{c o}\right) L
$$

Where, $W=$ width of the module, $D_{c o}=$ Glass absorber outer Diameter, $L=$ Length of the trough, $I=$ Total insolation. Out of total power input, the amount of power captivated by the parabolic trough collector; $\mathrm{Q}_{a}$

$$
Q_{a}=I_{b} A_{a} N_{c} N_{\gamma} N_{m} \rho \tau_{g} \alpha_{a}(I F)
$$

Calculation of losses and temperature is carried out through the iteration process. Heat transfer from the glass envelop occurs by convection and radiation:

$$
\begin{aligned}
& Q_{c-s}^{\prime}=\pi D_{c o} L h_{w(a i r)}\left(T_{c o}-T_{a}\right) \\
& +\pi \varepsilon_{c} D_{c o} L \sigma\left(T_{c o}^{4}-T_{s}^{4}\right)
\end{aligned}
$$

Where, Convective Heat transfer coefficient $h_{w}$ (air), can be calculated by McAdams correlation.

$$
\begin{aligned}
& \frac{h_{w} D_{c o}}{k_{\text {air }}}=0.04+0.54\left(\frac{\rho_{\text {air }} V_{w} D_{c o}}{\mu_{\text {air }}}\right)^{0.52} \\
& \text { For } 0.1<\operatorname{Re}<1000 \\
& \frac{h_{w} D_{c o}}{k_{\text {air }}}=0.3\left(\frac{\rho_{\text {air }} V_{w} D_{c o}}{\mu_{\text {air }}}\right)^{0.6} \\
& \text { For } 1000<\operatorname{Re}<50000
\end{aligned}
$$

Useful Heat Gain (Qu) of the absorber/receiver is calculated as.

$$
Q_{u}=\left[(\rho \tau \alpha) \times\left(\pi D_{c o} L\right) \times I_{b}\right]-Q_{c-s}^{\prime}
$$

Calculating receiver tube temperature:

$$
T_{r}=T_{f m}+\frac{Q_{u}}{\pi D_{i} h_{f}}
$$

The value of mass flow rate $\&$ heat transfer coefficient of the fluid is considered in the succeeding set of equations.

(8)

$$
\begin{gathered}
m_{f}=\frac{Q_{u}}{\Delta T \times C_{p}} \\
\mathbf{R e}=\frac{4 \times m_{f}}{\pi \times D_{i} \times \mu}
\end{gathered}
$$


(10)

$$
\operatorname{Pr}=\frac{\mu \times C p}{K_{f}}
$$

If $\operatorname{Re}<2300$

$$
N u=3.66+\frac{0.668 \operatorname{Re} \times \operatorname{Pr} \times D_{i}}{1+\left(0.04 \times \operatorname{Re} \times \operatorname{Pr} \times D_{i}\right)^{0.23}}
$$

If $\operatorname{Re}>2300$

$N u=0.023 \operatorname{Re}^{0.8} \operatorname{Pr}^{(1 / 3)}$

Heat transfer coefficient is given as

$$
h_{f}=\frac{N u \times K_{f}}{D_{i}}
$$

The inner glass cover temperature is calculated as

$$
T_{c i}=\left(\frac{Q_{l(c-a)} \times \ln \frac{D_{c o}}{D_{c i}}}{2 \pi K_{c} L}\right)+T_{c o}
$$

Heat loss from the receiver to the glass envelop is considered through radiation, which is calculated as.

$$
Q_{r-c}^{\prime}=\frac{\pi D_{o} \sigma\left(T_{r}^{4}-T_{c i}^{4}\right)}{\left[\frac{1}{\varepsilon_{r}}+\frac{D_{o}}{D_{c i}}\left(\frac{1}{\varepsilon_{c}}-1\right)\right]}
$$

The iteration process is to be accomplished by linking the heat transfer equations. If the values are found to be equal in Equation 4 and equation 14, additional procedures are followed. If both values are unequal, another slightly higher value of $T_{c o}$ is supposed to be assumed and further, the iteration steps are repeated to obtain the results.

The overall heat loss coefficient is determined by

$$
U_{l}=\frac{Q_{\text {loss }}}{\pi \times D_{i} \times L\left(T_{r}-T_{a}\right)}
$$

Further collector heat removal factor $\left(F_{r}\right)$ is found by

$$
F_{r}=\frac{m C_{p}}{U_{l} A_{r}} 1-e^{\left[\frac{U_{l} A_{r} F^{\prime}}{m C_{p}}\right]}
$$

The Collector efficiency factor $\left(F^{\prime}\right)$, the ratio of useful gained energy to the energy collected is determined by [22]

$$
F^{\prime}=\frac{1 / U_{l}}{\frac{1}{U_{l}}+\frac{D_{o}}{D i h_{f}}+\frac{D_{o}}{2 K_{r}} \ln \frac{D_{o}}{D_{i}}}
$$


Useful heat gain by the thermic fluid is calculated as

$$
Q_{u u}=F_{r}\left[Q_{a}-U_{l} A_{r}\left(T_{i}-T_{a}\right)\right]
$$

The thermal collector efficiency $\left(\eta_{\text {th }}\right)$ is defined as the useful energy gain ( $\left.Q_{u u}\right)$ to the incident solar energy over a specific period and is calculated as

$$
\eta_{t h}=\frac{Q_{u u}}{Q_{I}}
$$

Pressure loss $\Delta \mathrm{Pf}$ of the thermic fluid through the receiver tube is calculated by friction factor (f) and velocity of thermic fluid.

$$
\begin{aligned}
& \text { If } \operatorname{Re}<2300 \\
& f=16 / \operatorname{Re}
\end{aligned}
$$

$$
\begin{aligned}
& \text { If } \operatorname{Re}>2300 \\
& f=0.0791 \times(\operatorname{Re})^{-0.25}
\end{aligned}
$$

$$
V_{f}=\frac{m_{f}}{\frac{\pi}{4} D i^{2} \rho_{f}}
$$

Exergy destruction in the receiver tube is due to pressure drop, which adds up to the pumping power to make the fluid flow through the tube.

$$
E_{\text {desp }}=m_{f} \times T_{a m .} \frac{\Delta p_{f}}{\rho_{f m} \times T_{f m}}
$$

The exergy destruction because of heat loss from the receiver tube is calculated as

$$
E_{\text {desu }}=m_{f} \times C_{p} \times T_{\text {am }} \times \ln \left[\frac{T_{\text {out }}}{T_{\text {in }}}\right]
$$

The useful exergy is determined by

$$
E_{u}=Q_{u}-E_{\text {desp }}-E_{\text {desu }}
$$

The exergy flow of the incoming solar irradiation $\left(E_{s}\right)$ is considered through the Petela model, according to the succeeding equation [22].

$$
E_{s}=Q_{s}\left[1-\frac{4}{3}\left(\frac{T_{a m}}{T_{\text {sun }}}\right)+\frac{1}{3}\left(\frac{T_{a m}}{T_{s u n}}\right)^{4}\right]
$$


The exergetic efficiency $\left(\eta_{e x}\right)$ is defined as the fraction of useful exergy output to the exergy flow of sun.

$$
\eta_{e x}=\frac{E_{u}}{E_{s}}
$$

\section{Results and discussion}

The analysis of the parabolic trough of the solar collector is carried out using the performance parameters, namely, overall loss coefficient, useful heat gain, thermal, and energetic efficiency, have been evaluated as a function of major system design parameters, namely, mirror reflectivity, the diameter of the fluid, carrier tube, transmissivity-absorptivity product; and major operating parameters, namely isolation and temperature rise parameter. The performance parameters value is displayed in figures with the temperature rise parameter, to bring out its effect on various performance parameters. The value of the selected parameter varies in each figure, while the other parameters have a set of fixed values.

For instance, Figure 1 shows the effect of reflectivity of the mirror on the useful heat gain, where it can be seen that with an increase in reflectivity of the mirror from 0.72 to 0.92 , the magnitude of the useful heat gain enhances, this is because as the mirror reflectivity increase, large amount of energy is reflected by the absorber tube, hence an increase in useful heat gain is observed.

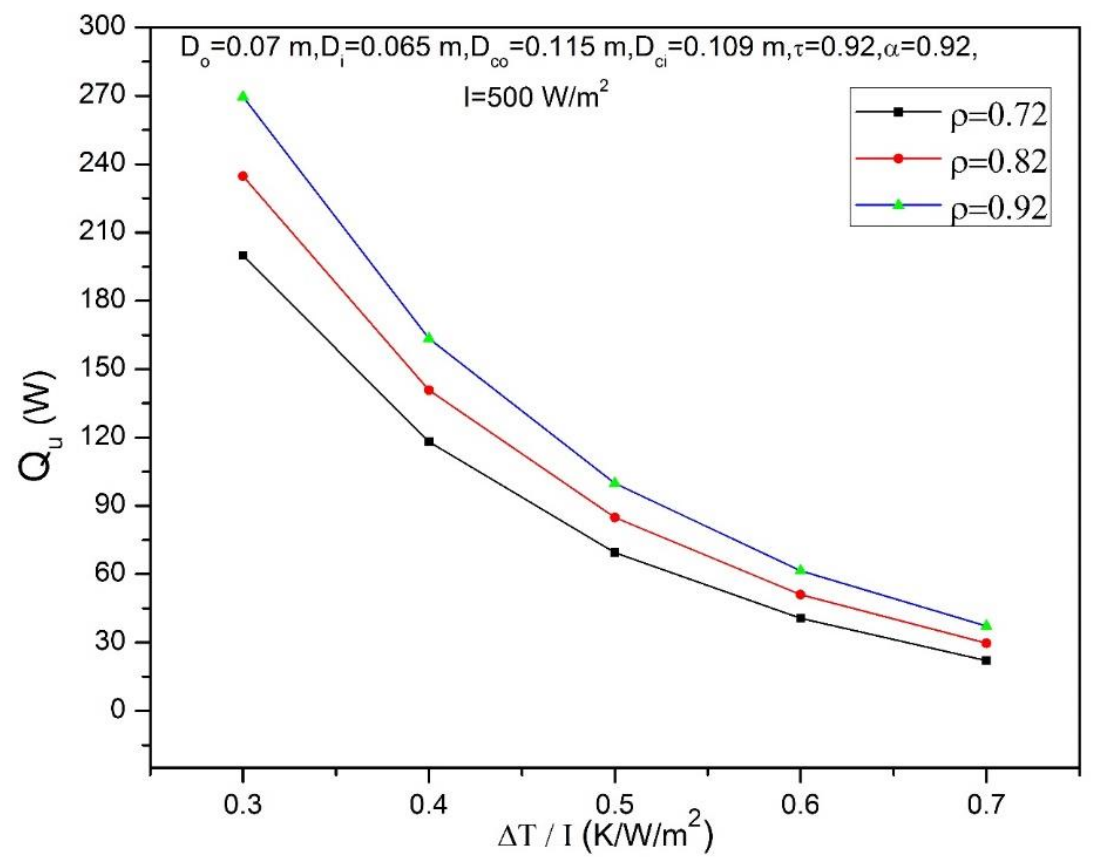

Fig. 1. Effect of variation of mirror reflectivity on useful heat gain

Figure 2 shows the effect of reflectivity of mirror glass on the useful heat gain and thermal efficiency. It can be seen that with the decrease in mirror reflectivity, the loss decreases, which increases the useful heat gain. This is responsible for increase in the thermal efficiency. Even though the effect of reflectivity is very small for bringing change in the thermal efficiency, for different temperature rise parameter values. As the value of the temperature rise parameter is increased, the thermal efficiency comes down, it is well known that when $\Delta T$ is very low, the absorber cover temperature is minimum. This lower temperature leads to the small amount of heat loss to the environment, thus resulting in the highest thermal efficiency. 


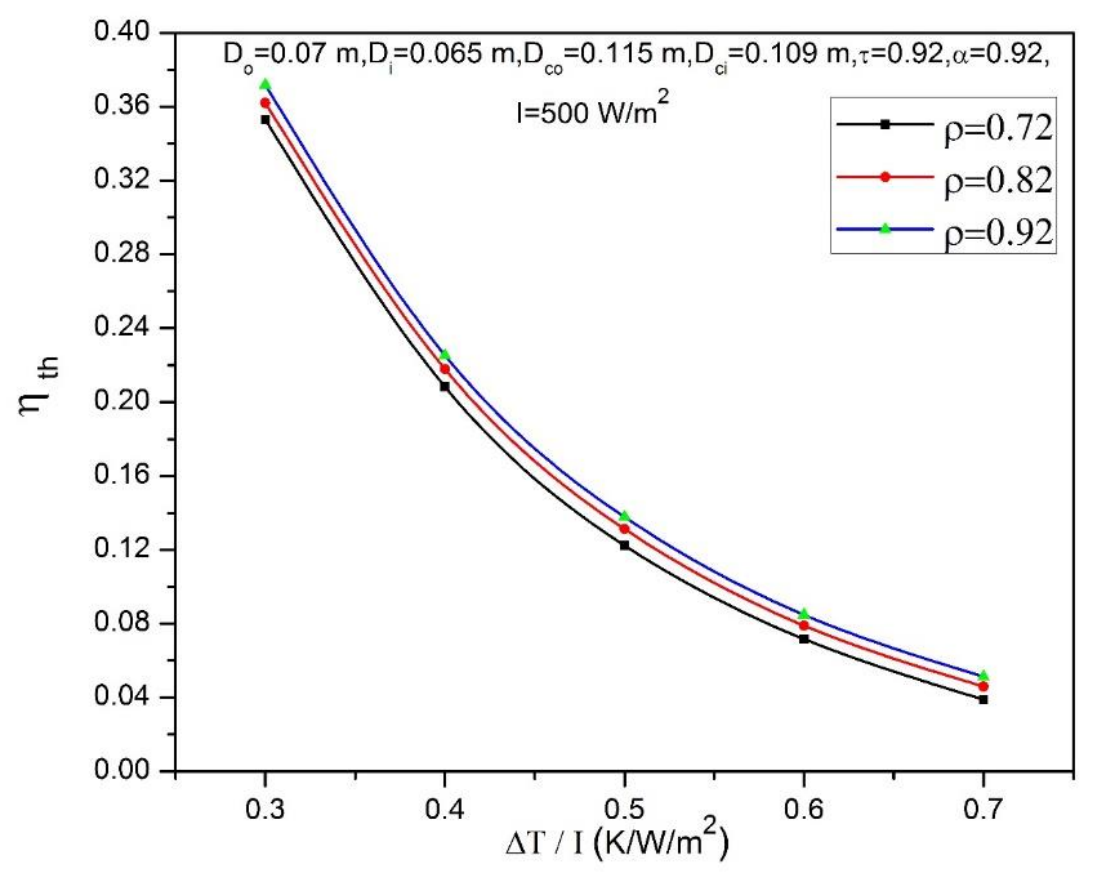

Fig. 2. Effect of variation of mirror reflectivity on thermal efficiency

Figure 3 shows the effect of mirror reflectivity on exergetic efficiency. It is seen that with rise in the temperature rise parameter, a significant enhancement in the energetic efficiency is observed. However, beyond the temperature rise parameter value of 0.3 , the energetic efficiency decreases. To absorb high thermal energy at a low value of temperature rise, the flow rate of HTF is very high, which results in a large amount of friction loss. Hence, the combination of high friction loss and a low amount of thermal gain results in a very low value of energetic efficiency. Whereas at high value of temperature rise parameter $(<0.3)$, the temperature of the fluid is very high resulting in heat loss and vis-a-vis exergy destruction and hence the sudden decline of energetic efficiency4df.

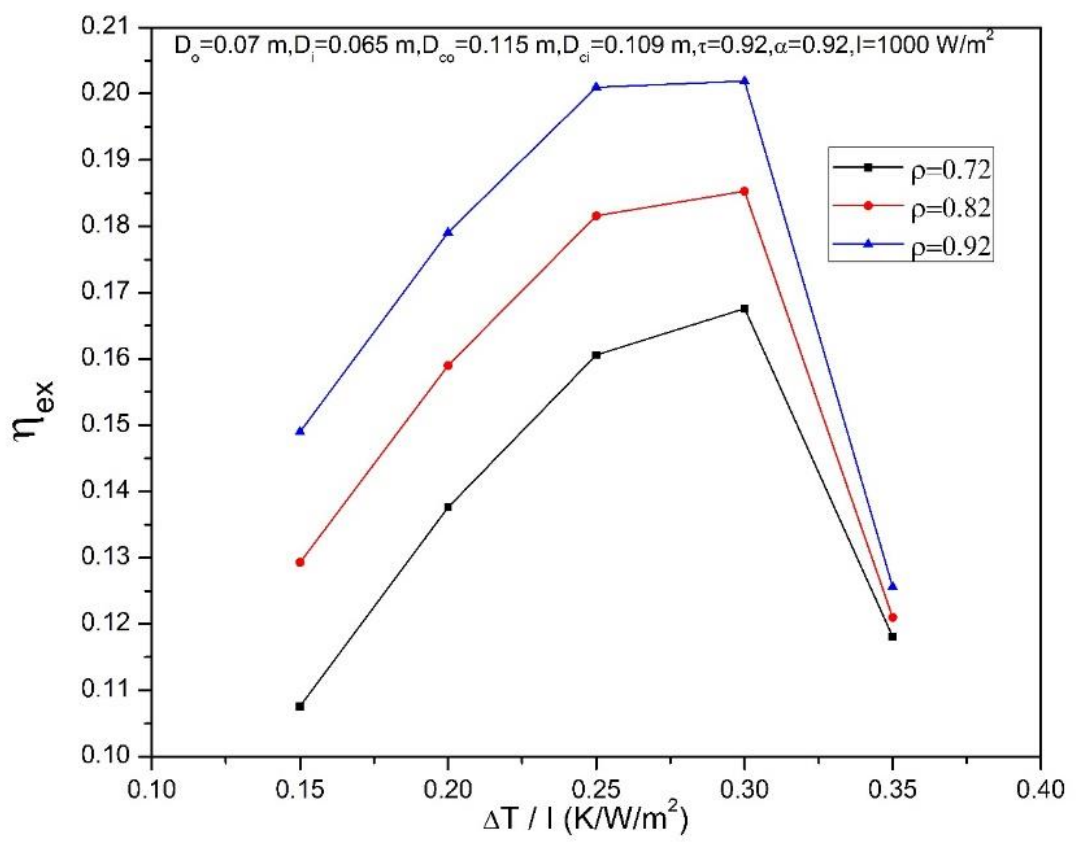

Fig. 3. Effect of variation of mirror reflectivity on exergetic efficiency 
Figures $4 \& 5$ shows the effect of different effective transmittance products on the thermal efficiency for fixed values of other parameters corresponding to the insolation values of $500 \mathrm{~W} / \mathrm{m}^{2}$ and $1000 \mathrm{~W} / \mathrm{m}^{2}$ respectively. It is seen that a higher value of $\alpha \alpha$ results in a slightly higher efficiency, although the effect is more visible in the case of a lower insolation value. At a fixed value of $\Delta T / I=0.5$, and increasing the ta from 0.74 to 0.94 , an increase in thermal efficiency of $12 \%$ to $17 \%$ is observed. This represents a substantial change as a result of the changing products of transmittance absorptance. An increase in this product results in a higher amount of insolation being ultimately absorbed, leading to higher thermal gain.

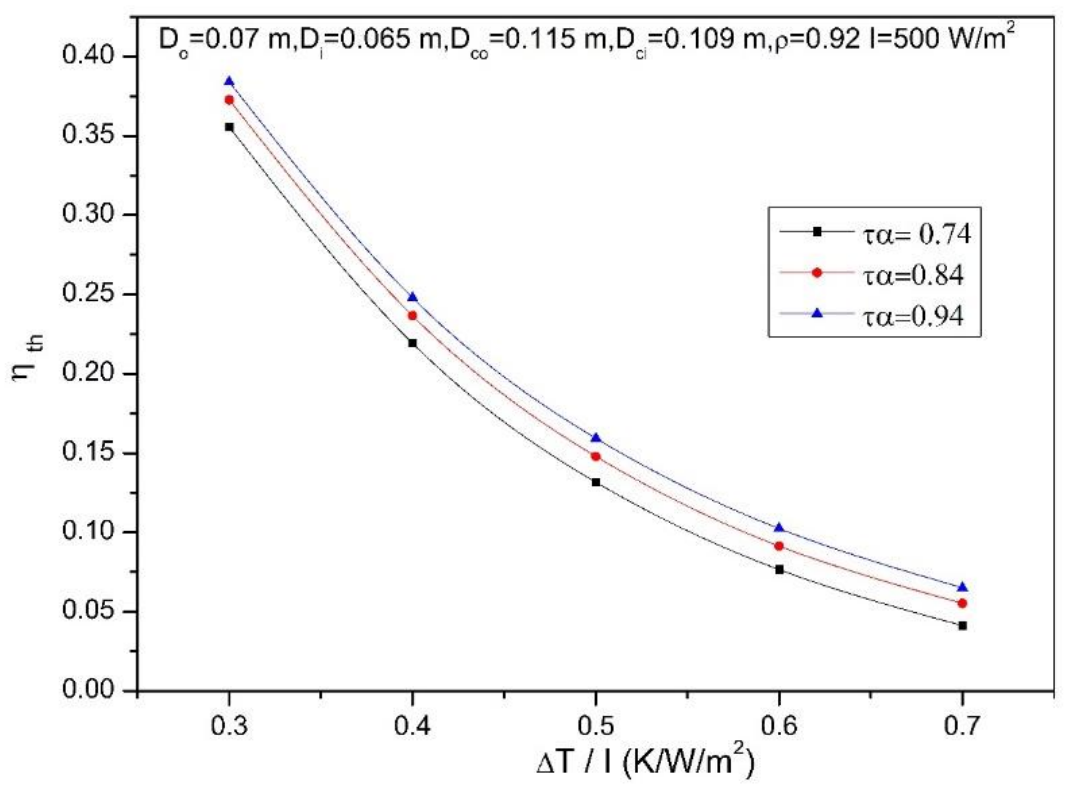

Fig. 4. Effect of variation of transmissivity and absorptivity on thermal efficiency at I $=500 \mathrm{~W} / \mathrm{m}^{2}$

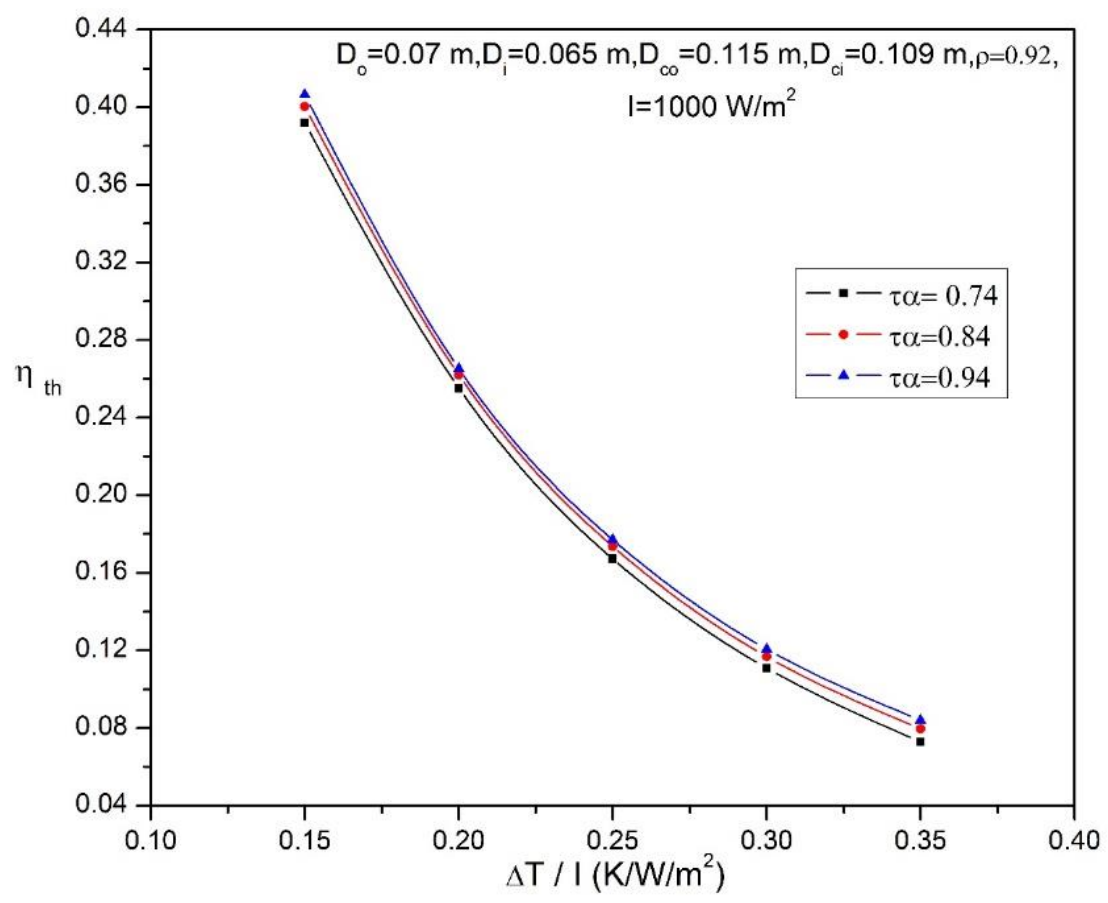

Fig. 5. Effect of variation of Transmissivity and absorptivity on thermal efficiency at $\mathrm{I}=1000 \mathrm{~W} / \mathrm{m}^{2}$ 


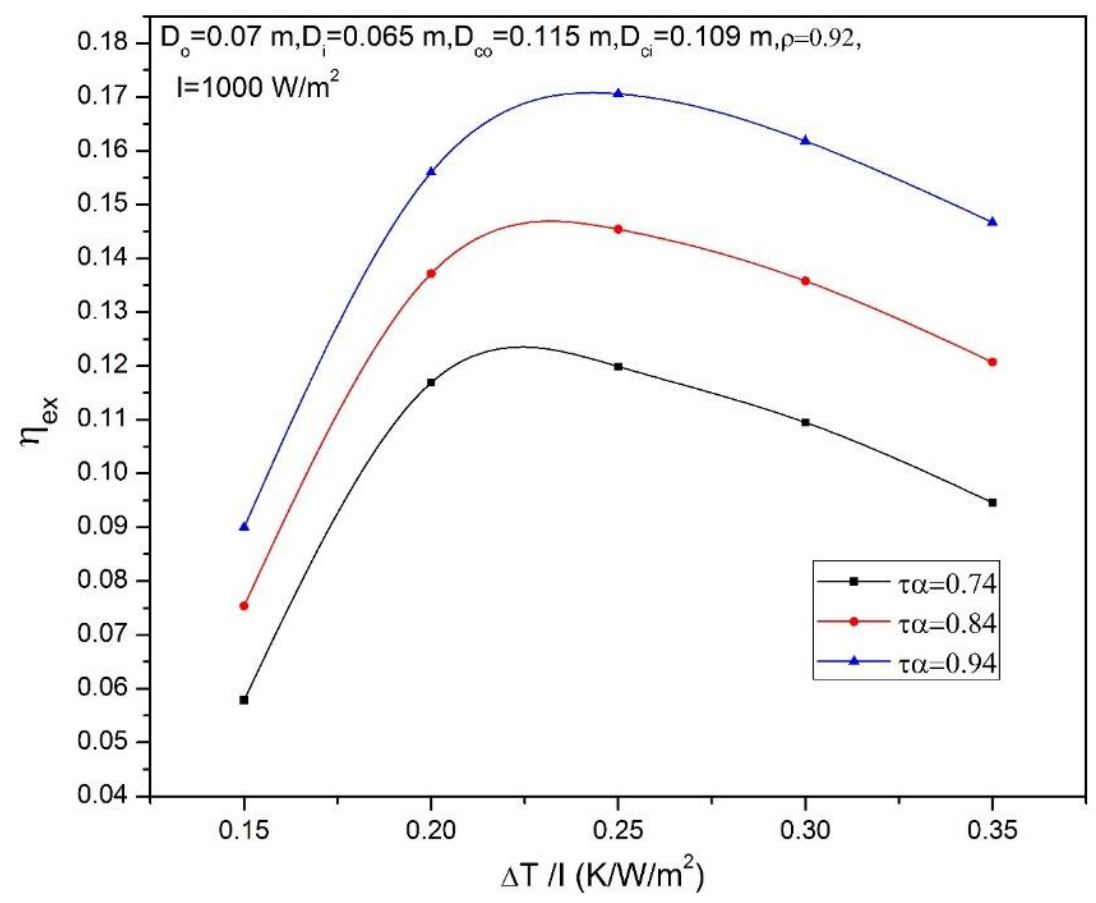

Fig. 6. Effect of variation of transmissivity and absorptivity on exergetic efficiency

The effect of effective transmittance-absorptance product on energetic efficiency has been depicted in the Figure 6 . It is noteworthy that the exergetic efficiency is very strongly affected by the variation of $\tau \alpha$. The figure reveals that at lower temperature rise parameter value, the results of performance of system does not vary too much for change in the transmittance absorptance product. Whereas this variation is wider at higher magnitude of temperature rise parameter. Higher exergetic efficiencies with an increase in transmittance - absorptance products show that a better quality of energy is obtained.

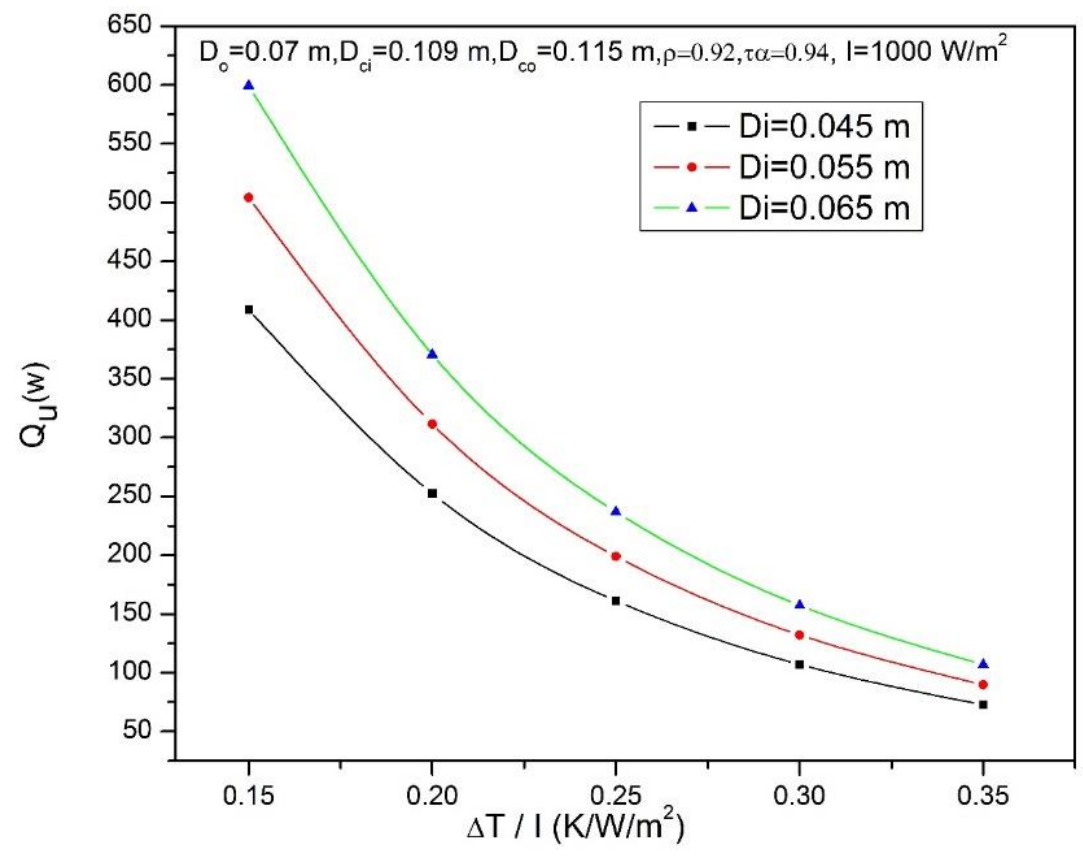

Fig. 7. Effect of variation of receiver tube diameter on useful heat gain of fluid 
The effect of diameter on performance parameters can be seen in Figs. 7 and 8. It is seen that a larger diameter results in a slightly higher value of useful heat gain, thermal and exergetic efficiencies. Although the effect seems to minimize at a higher value of temperature rise parameter.

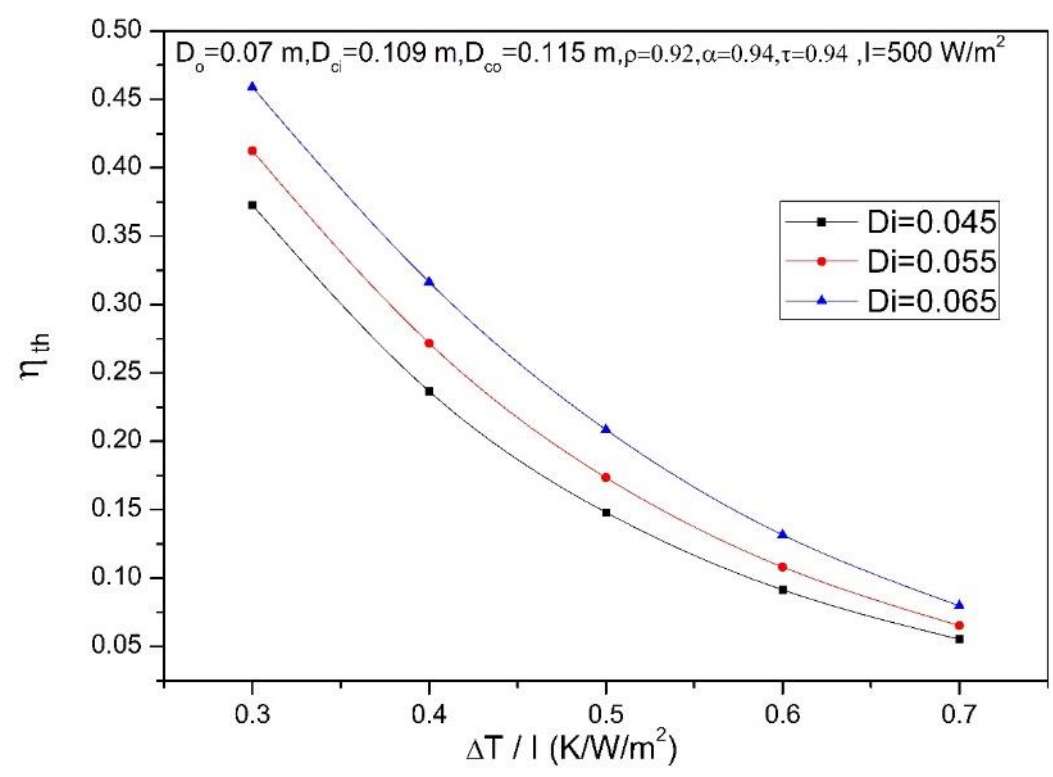

Fig. 8. Effect of variation of receiver tube diameter on thermal efficiency

Fig. 9 shows the effect of diameter on exergetic efficiency, it is noteworthy that the exergetic efficiency values are strongly affected by the values of the temperature rise parameter. For the minimum value of temperature rise parameter and smaller receiver inner diameter, a high rate of fluid flow is seen, which resulted in the higher friction loss in the system observed. This low exergy gain and high amount of friction loss results in a negative value of exergetic efficiency; hence at a lower value of temperature rise parameter, the low diameter of the receiver tube becomes unacceptable.

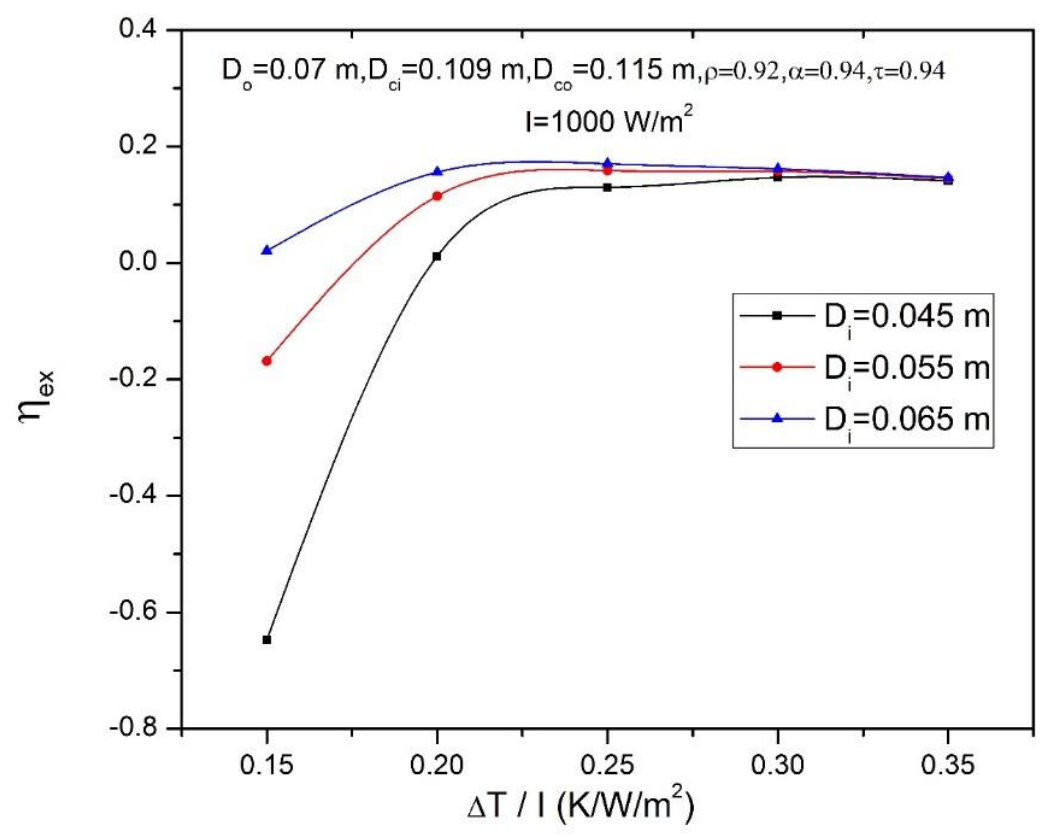

Fig. 9. Effect of variation of receiver tube diameter on exergetic efficiency 


\section{Impact}

The present analysis of parabolic trough concentrated solar power plant deals with the energy and exergy component of the system. The analysis is carried out to fetch the best suited set of parameters that are prolific for enhancing the performance of the parabolic trough concentrated solar power plant. The present analysis will have an impact on determining the working condition of the power plant on the basis of fluid temperature. This analysis will lead to the development of renewable source for power generation as well as will also take care of the environmental aspect, which is damaged by other fuels used in power plants operations.

\section{Conclusions}

The CSP Parabolic Trough analysis by simulation technique carried out to investigate the effect of dominant design parameters in a power plant viz. transmittance-absorptance product, mirror reflectivity, receiver tube diameter. The designed system is analysed based on the thermal and exergetic performance. It is seen that performance of the trough is low as the $\Delta T$ magnitude increases. The exergetic efficiency seems to get better by increase in $\Delta \mathrm{T}$. The results revealed that the operating the system at higher temperatures is prolific as compared to lower temperature. Following are the major conclusions:

- The transmittance-absorptance product has a negligible effect on the thermal efficiency of the system, whereas the exergetic efficiency is seen to improve with increasing value of $\alpha$. Better exergetic performance resulting from higher transmittance product shows that a better quality of energy is obtained.

- A higher value of reflectivity for better thermal and exergetic efficiency is recommended.

Although the benefit of using a larger receiver tube with a larger diameter is not visible for a higher value of temperature rise parameter, for the low value of temperature rise, it is not recommended to use a smaller receiver tube with a small diameter.

\section{Conflict of interest}

There are no conflicts to declare.

\section{Acknowledgments}

This research has not been supported by any external funding.

\section{References}

[1] F. Lippke, Simulation of the part-load behavior of a 30 MWe SEGS plant, United States, 1995. https://doi.org/doi.org/10.2172/95571.

[2] S. Kalogirou, S. Lloyd, J. Ward, Modelling, optimisation and performance evaluation of a parabolic trough solar collector steam generation system, Sol. Energy. 60 (1997) 49-59. https://doi.org/10.1016/S0038092X(96)00131-4.

[3] E. Zarza, L. Valenzuela, J. León, K. Hennecke, M. Eck, H.D. Weyers, M. Eickhoff, Direct steam generation in parabolic troughs: Final results and conclusions of the DISS project, Energy. 29 (2004) 635-644. https://doi.org/10.1016/S0360-5442(03)00172-5.

[4] E. Prabhu, Solar trough Organic Rankine electricity system (STORES) stage 1: power plant Optimization and economics, California, 2006.

[5] Z. Wu, S. Li, G. Yuan, D. Lei, Z. Wang, Three-dimensional numerical study of heat transfer characteristics of parabolic trough receiver, Appl. Energy. $113 \quad$ (2014) 902-911. https://doi.org/10.1016/j.apenergy.2013.07.050.

[6] D. Canavarro, J. Chaves, M. Collares-Pereira, New optical designs for large parabolic troughs, Energy Procedia. 49 (2014) 1279-1287. https://doi.org/10.1016/j.egypro.2014.03.137.

[7] A.M. De Oliveira Siqueira, P.E.N. Gomes, L. Torrezani, E.O. Lucas, G.M. Da Cruz Pereira, Heat transfer analysis and modeling of a parabolic trough solar collector: An analysis, Energy Procedia. 57 (2014) 401410. https://doi.org/10.1016/j.egypro.2014.10.193.

[8] L. Guzman, A. Henao, R. Vasqueza, Simulation and optimization of a parabolic trough solar power plant in the city of Barranquilla by using system advisor model (SAM), Energy Procedia. 57 (2014) 497-506. https://doi.org/10.1016/j.egypro.2014.10.203.

[9] A. Messai, Y. Benkedda, S. Bouaichaoui, M. Benzerga, Feasibility study of parabolic trough solar power plant under Algerian climate, Energy Procedia. 42 (2013) 73-82. 
https://doi.org/10.1016/j.egypro.2013.11.007.

[10] A.S. Pidaparthi, N.R. Prasad, India's first solar thermal parabolic trough pilot power plant, Energy Procedia. 49 (2014) 1840-1847. https://doi.org/10.1016/j.egypro.2014.03.195.

[11] M. Douani, A. Labbaci, H. Hadj Benaichouche, Analysis of the energetic feasibility of parabolic trough collectors integrated in solar towers in Adrar area, Energy Procedia. 36 (2013) 1085-1100. https://doi.org/10.1016/j.egypro.2013.07.124.

[12] P. Daniel, Y. Joshi, A.K. Das, Numerical investigation of parabolic trough receiver performance with outer vacuum shell, Sol. Energy. 85 (2011) 1910-1914. https://doi.org/10.1016/j.solener.2011.04.032.

[13] J. Muñoz, J.M. Martinez-Val, A. Ramos, Thermal regimes in solar-thermal linear collectors, Sol. Energy. 85 (2011) 857-870. https://doi.org/10.1016/j.solener.2011.02.004.

[14] M. Eck, T. Hirsch, Dynamics and control of parabolic trough collector loops with direct steam generation, Sol. Energy. 81 (2007) 268-279. https://doi.org/10.1016/j.solener.2006.01.008.

[15] A. El Fadar, A. Mimet, M. Pérez-García, Modelling and performance study of a continuous adsorption refrigeration system driven by parabolic trough solar collector, Sol. Energy. 83 (2009) 850-861. https://doi.org/10.1016/j.solener.2008.12.003.

[16] I. Llorente García, J.L. Álvarez, D. Blanco, Performance model for parabolic trough solar thermal power plants with thermal storage: Comparison to operating plant data, Sol. Energy. 85 (2011) 2443-2460. https://doi.org/10.1016/j.solener.2011.07.002.

[17] C.Y. Tsai, P.D. Lin, Optimized variable-focus-parabolic-trough reflector for solar thermal concentrator system, Sol. Energy. 86 (2012) 1164-1172. https://doi.org/10.1016/j.solener.2012.01.009.

[18] M.K. Gupta, S.C. Kaushik, Exergy analysis and investigation for various feed water heaters of direct steam generation solar-thermal power plant, Renew. Energy. 35 (2010) 1228-1235. https://doi.org/10.1016/j.renene.2009.09.007.

[19] I.H. Aljundi, Energy and exergy analysis of a steam power plant in Jordan, Appl. Therm. Eng. 29 (2009) 324-328. https://doi.org/10.1016/j.applthermaleng.2008.02.029.

[20] V.S. Reddy, S.C. Kaushik, S.K. Tyagi, Exergetic analysis and performance evaluation of parabolic trough concentrating solar thermal power plant (PTCSTPP), Energy. 39 (2012) 258-273. https://doi.org/10.1016/j.energy.2012.01.023.

[21] S. Bespalko, A.M. Miranda, O. Halychyi, Overview of the existing heat storage technologies: sensible heat, Acta Innov. (2018) 82-113. https://doi.org/10.32933/actainnovations.28.8.

[22] R. Petela, Exergy of heat radiation, J. Heat Transfer. $86 \quad$ (1964) $187-192$. https://doi.org/10.1115/1.3687092. 